\title{
How to Perform and Interpret a High-resolution Anorectal Manometry Test
}

\author{
Tae Hee Lee ${ }^{1}$ and Adil E Bharucha ${ }^{2 *}$ \\ ${ }^{1}$ Institute for Digestive Research, Soonchunhyang University Seoul Hospital, Seoul, Korea; and ${ }^{2}$ Clinical Enteric Neuroscience Translational and \\ Epidemiological Research, Mayo Clinic and Mayo Foundation, Rochester, Minnesota, USA
}

High-resolution anorectal manometry (HR-ARM) and high-definition anorectal manometry (HD-ARM) catheters have closely spaced water-perfused or solid state circumferentially-oriented pressure sensors that provide much better spatiotemporal pressurization than non-high resolution catheters. This is a comprehensive review of HR-ARM and HD-ARM anorectal manometry catheter systems, the methods for conducting, analyzing, and interpreting HR-ARM and HD-ARM, and a comparison of HR-ARM with non-high resolution anorectal manometry. Compared to non-high resolution techniques, HR-ARM and HD-ARM studies take less time and are easier to interpret. However, HR-ARM and HD-ARM catheters are more expensive and fragile and have a shorter lifespan. Further studies are needed to refine our understanding of normal values and to rigorously evaluate the incremental clinical utility of HR-ARM or HD-ARM compared to non-high resolution manometry.

(J Neurogastroenterol Motil 2016;22:46-59)

Key Words

Anal canal; Constipation; Fecal incontinence; Manometry; Physiology

\section{Introduction}

Anorectal manometry (ARM) and rectal balloon expulsion tests are widely used for diagnosing defecatory disorders in constipated patients. ${ }^{1-4}$ ARM is also useful for identifying reduced anal pressures at rest and during squeeze in fecal incontinence. ${ }^{5,6}$ Prior to the introduction of high-resolution manometry catheters in 2007, anorectal manometry was performed with non-high resolution, water-perfused or solid state catheters. Since then, high-resolution anorectal manometry (HR-ARM) and high-definition anorectal manometry (HD-ARM) catheters are increasingly used in clinical practice. While older, "non-high resolution" catheters have three or six unidirectional sensors, HR-ARM and HD-ARM catheters contain several closely spaced circumferential sensor elements along the longitudinal axis. The pressure-sensing element varies among systems. In catheters manufactured by Given Imaging (Yoqneam, Israel), this comprises 16 (ManoScan HD-ARM catheter) or 36 circumferential sensors (ManoScan HR-ARM catheter). Unisensor catheters (UniTip, Attikon, Switzerland) are comprised of a unidirectional pressure sensor embedded within a soft membrane containing silicone gel. ${ }^{7}$ The catheter manufactured by Sandhill has 4 radially-arranged sensors at each level. ${ }^{8}$ Water-perfused high resolution catheters (Mui Scientific, Mississauga, Ontario, Canada) are

\section{Received: October 13, 2015 Revised: November 20, 2015 Accepted: December 11, 2015}

() This is an Open Access article distributed under the terms of the Creative Commons Attribution Non-Commercial License (http://creativecommons. org/licenses/by-nc/4.0) which permits unrestricted non-commercial use, distribution, and reproduction in any medium, provided the original work is properly cited.

*Correspondence: Adil E Bharucha, MBBS, MD

Clinical Enteric Neuroscience Translational and Epidemiological Research, Mayo Clinic and Mayo Foundation, Mayo Clinic 200 First Street S.W. Rochester, MN 55905, USA

Tel: +1-507-284-2687, Fax: +1-507-538-5820, E-mail: bharucha.adil@mayo.edu 
also available.

HR-ARM and non-HRM catheters are compared in Table 1. HR-ARM and HD-ARM catheters provide a continuous and dynamic spatiotemporal mapping of anorectal pressures, allowing easier and more detailed data interpretation. ${ }^{9-12}$ While HR-ARM and HD-ARM both measure pressures around the circumference of the catheter, only HD-ARM provides the pressures measured by individual sensors around the catheter circumference. ${ }^{12,13}$ The duration of the examination is also significantly shorter with HRARM than with non-HRM because the former does not require a pull-through procedure, and the topographic display enables rapid positioning of the probe. ${ }^{10,11}$ However, HR-ARM and HD-ARM catheters are more expensive and fragile than non-high resolution catheters and have a shorter lifespan. ${ }^{12}$ For example, ManoScan catheters are guaranteed for 200 uses only. Also, pressure measurements with ManoScan sensors are affected by differences between the environmental temperature, when calibration is performed, and the body temperature. A "thermal compensation" algorithm embedded within the acquisition software is applied after the study to correct for this phenomenon. However, recent observations with esophageal ManoScan catheters suggest that this pressure drift is related to "average pressure exposure" of a sensor during the study procedure and may not be adequately corrected with the thermal compensation algorithm. ${ }^{14}$ In addition, while pressures recorded with HR-ARM and non-high resolution manometry are significantly correlated, ${ }^{9-11,15}$ anal sphincter pressures at rest and during anal contraction (ie, squeeze maneuver) tend to be higher when measured with HR-ARM than when measured with non-high resolution manometry. ${ }^{9-11}$ The rectoanal pressure gradient measured with both techniques was also strongly correlated; however the gradient was more negative for non-high resolution $(-66 \mathrm{mmHg})$ than HR-ARM, ${ }^{10}$ even in healthy women.

\section{Test Equipment}

HR-ARM is conducted with water-perfused or solid-state catheters. Water-perfused manometry requires more preparation, technical skills, and training. ${ }^{16}$ The dynamic performance of waterperfused systems is several orders of magnitude less than that of solid-state systems, limiting their accuracy where rapidly changing pressures must be measured (eg, in the pharynx/upper esophageal sphincter). ${ }^{16}$ However, this is not a limitation in the anorectum where rapidly changing pressures are not observed.

\section{High-resolution Anorectal Manometry System}

\section{Given imaging high-resolution anorectal manometry- system}

There are 2 versions of this solid-state catheter (ManoScan AR catheter), which has an outer diameter of $4.2 \mathrm{~mm}$. The regular probe (AAN) has 12 circumferential sensors, including ten sensors at 6-mm intervals along the anal canal and two sensors in the rectal balloon (3.3 cm long, maximum capacity of $400 \mathrm{~mL}$ ) (Fig. 1A). The small probe (APN) has 8 circumferential sensors, including 1 balloon sensor. The manufacturer recommends a latex free rectal balloon that is $3.3 \mathrm{~cm}$ long and has a maximal capacity of $400 \mathrm{~mL}$. Indeed the manufacturer's recommended rectal balloons for all HR-ARM catheters cited in this review have similar dimensions. Both catheters have 36 circumferentially oriented, pressure-sensing elements (TactArray; Pressure Profile Systems, Los Angeles, California) that acquire data at $35 \mathrm{~Hz}$. These 36 sector pressures are then averaged to yield a single value. The response characteristics of each sensing element are such that pressure transients $>6000$ $\mathrm{mmHg} / \mathrm{sec}$ can be recorded with an accuracy that is within 1 $\mathrm{mmHg}$ of atmospheric pressure for measurements obtained during

Table 1. Qualitative Comparison of High-resolution and High-definition Anorectal Manometry Catheters Versus Non-high Resolution Anorectal Manometry Catheters

\begin{tabular}{lll}
\hline & HR-ARM and HD-ARM & Non-HRM \\
\hline Number of sensors & Closely spaced more sensors & Fewer sensors at wider intervals \\
Display & Color contour and line plot & Line plot \\
Techniques & Stationary examination & Pull-through examination \\
Preparation & Easy & More time consuming \\
Spatiotemporal resolution & Good & Limited \\
Cost & High & Low \\
Catheter durability & Limited & Excellent \\
Lifespan & Limited & Excellent \\
\hline
\end{tabular}

HR-ARM, high-resolution anorectal manometry; HD-ARM, high-definition anorectal manometry. 

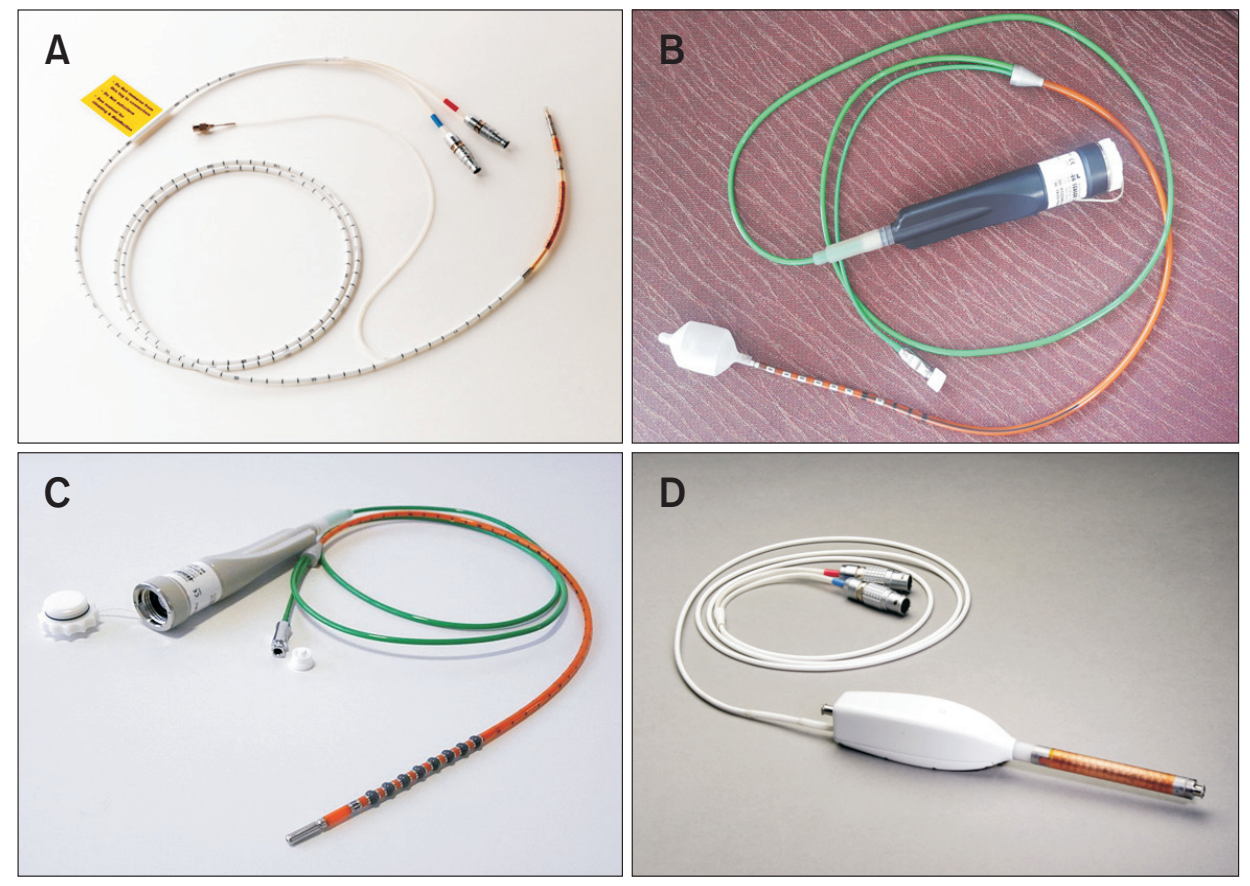

Figure 1. Catheter design. High-resolution anorectal manometry catheters manufactured by (A) Given Imaging, (B) Sandhill Scientific, and (C) Medical Measurement Systems. (D) shows a high definition manometry catheter made by Given Imaging.

aat least the final 5 minutes of the study, immediately before thermal recalibration. However, these sensors are susceptible to "thermal drift", that is, a change in measured pressure due to a change in temperature. ${ }^{17}$ An in vitro study suggested (1) that this drift was comprised of an initial change in pressure associated with change in temperature, termed thermal effect, and an ongoing pressure drift with time, termed baseline drift, (2) the drift is linear but varies among sensors, and (3) the thermal compensation algorithm in this system corrects for thermal effect but not for baseline drift. ${ }^{17}$ An audit of 560 esophageal high-resolution manometry (HRM) studies concluded that pressure drift (PD) is greater for sensors that record from the esophageal high-pressure zones than the pharynx and is strongly correlated with the "average pressure exposure" of a sensor during manometry. ${ }^{14}$ The available software algorithms do not adequately correct the PD. ${ }^{14}$ Further studies are necessary to assess the PD during anorectal manometry and whether the thermal compensation program adequately corrects for the same.

The data are acquired and displayed using the ManoScan AR analysis software (Given Imaging). The eSleeve option in the software reduces pressures recorded across the longitudinal extent of the anal canal into a single value. At rest, during squeeze, and rectal distention the eSleeve identifies the highest of all pressures recorded by anal sensors at every point in time. This eSleeve value is used to calculate the average and maximum anal resting pressure and the maximum squeeze pressure over 20 seconds during these maneu- vers. In addition to these absolute pressures, pressures referenced to the rectal pressure are reported. During simulated evacuation, the eSleeve identifies the most positive (or least negative) difference (ie, rectoanal gradient) between rectal and anal (rectal - anal) pressure over a 20 -seconds epoch. HR-ARM measurements of anal sphincter pressures at rest and during squeeze are higher than the corresponding pressures recorded with non-high resolution manometry because of the eSleeve function, which uses the highest pressures recorded at any level of the anal canal at every instant in time. ${ }^{10}$

\section{Sandhill high-resolution anorectal manometry system}

The probe (4-mm outer diameter; Sandhill Scientific, Denver, CO, USA) has 8 directional solid-state sensors. The most proximal sensor is in the rectal balloon. Distal to that is a sensor in the rectum, 5 anal sensors, which are each separated by $10 \mathrm{~mm}$, and an external reference pressure sensor located $1 \mathrm{~cm}$ outside the anal verge (Fig. 1B). The pressures recorded by the anal sensors are averaged to provide the mean sphincter pressure. The manufacturer recommends a latex free rectal balloon that is $3.3 \mathrm{~cm}$ long and has a maximal capacity of $400 \mathrm{~mL}$. The data are analyzed using the Bioview analysis software with the InSIGHT G3 HRiM or InSIGHT Ultima system (Sandhill Scientific). 


\section{Medical measurement systems high-resolution anorectal manometry system}

The $12 \mathrm{~F}$ catheter (4 mm; UniTip, UniSensor, Switzerland) (Fig. 1C) probe incorporates 8 directional sensors along the long axis. Of these, 6 sensors are equidistant from each other and span $5 \mathrm{~cm}$. The most proximal sensor is located within a non-latex balloon ( $3.3 \mathrm{~cm}$ long, maximum capacity of $400 \mathrm{~mL}$ ) and is $2.5 \mathrm{~cm}$ proximal to the other sensors. The most distal sensor is located 2 $\mathrm{cm}$ below the most distal anal sensor and serves as an external reference. Before a study is initiated, the catheter is immersed in tepid water for at least $3 \mathrm{~min}$ to pre-wet the sensors, which are then zeroed to atmospheric pressure. Data acquisition and visualization are performed using a commercially available manometry system (Solar GI HRM v.9.1; MMS, Enschede, the Netherlands).

\section{High-definition Anorectal Manometry}

The HD-ARM probe (Given Imaging) is $6.4 \mathrm{~cm}$ in length and has an outer diameter of $10.75 \mathrm{~mm}$ (Fig. 1D). The sensing segment is composed of 256 sensing elements that are arranged in 16 rows, each of which has 16 circumferentially oriented sensor elements. The spacing between the sensors is $4 \mathrm{~mm}$ axially and 2 $\mathrm{mm}$ radially. Data from all 256 sensors can be displayed individually. The balloon is composed of a non-latex, clear, thermoplastic elastomer and is $3.3 \mathrm{~cm}$ long, with a maximum capacity of $400 \mathrm{~mL}$. This probe is the largest and stiffest of all HRM probes. It is the only probe which displays pressures recorded by individual sensors around the circumference. The manometry and topographic images are displayed on a computer monitor using specialized software (Motility Acquisition AR System v.2.2; Given Imaging). The system operates at a frequency response of $>20 \mathrm{~Hz}$, a scan rate of $10 \mathrm{~Hz}$, and an output resolution of $0.1 \mathrm{mmHg}$. The probe is calibrated immediately before the procedure by placing it in a calibration chamber, where it is zeroed to atmospheric pressure and set to a range of pressures up to $300 \mathrm{mmHg}$. The sensor calibration residual is $\pm 2 \mathrm{mmHg}$ in the $0-100 \mathrm{mmHg}$ range and $2 \%$ of the reading in the 100-300 $\mathrm{mmHg}$ range. The HD-ARM requires thermal compensation to correct for the pressure drift with time.

\section{Test Procedure}

Most manometry studies can be undertaken without a written consent form because the procedure poses a minimal risk to patients. However, graded balloon distension during the test should be carefully conducted to avoid rectal rupture, especially in patients who have previously undergone rectal surgery. ${ }^{18}$ The exact manometry protocols will vary by center. The procedure must include an assessment of rectoanal pressure and anal canal length at rest, rectoanal pressures during squeeze, simulated evacuation, and coughing, and, rectal sensation. A rectal balloon expulsion test, which is an effective screening test to identify defecatory disorders, should be performed at the same visit as the anorectal manometry. ${ }^{19}$

\section{Patient Preparation}

Bowel preparation is not routinely used. An enema is given if stool is detected on a digital rectal examination. At least 30 minutes should elapse from enema insertion to probe placement.

\section{Patient Position}

The patient is placed in the left lateral position with knees and hips bent at a $90^{\circ}$ angle.

\section{Probe Placement}

The lubricated probe is gently inserted into the rectum. The probe is oriented with its dorsal aspect corresponding to that of the patient. This allows for detailed reading of measurements from the rectum and anal canal with respect to probe orientation. The HDARM probe is thicker and more rigid than the probes used with HR-ARM and non-HRM and often does not conform to the anorectal angle. ${ }^{12}$ Once positioned, the probe assembly remains stationary for the duration of the study.

\section{Rest}

After probe placement, a run-in period of approximately 5 minutes should be allowed to give the patient time to relax such that anal sphincter tone returns to basal levels. Anal resting pressure is generally measured over 20 seconds. However, this duration is not sufficient to identify ultraslow wave activity, which is occasionally observed, has a frequency of 1 to 1.5 cycles/min, and is associated with either normal or increased anal resting pressures. ${ }^{20}$

\section{Squeeze}

The patient is asked to squeeze the anus for as long as possible, for a maximum of 30 seconds, followed by a 1-minute rest. By convention, this maneuver is performed three times. Ideally, rectal pressure should not increase, because that would imply that the patient has contracted the abdominal wall. With the HD-ARM assembly, it is important to continuously monitor and be aware of probe movement, especially after the patient performs maneuvers such as squeeze, cough, or bearing down, and to adjust the probe 
when necessary.

\section{Cough Reflex Test}

This maneuver is indicated to assess the integrity of spinal reflex pathways in patients with incontinence. The patient is asked to cough or inflate a balloon. Normally, the increased abdominal pressure triggers external sphincter contraction. The maneuver is repeated once more.

\section{Simulated Defecation}

The patient is asked to bear down as if to defecate. This test is conducted without and with distention of a $50-\mathrm{mL}$ rectal balloon, separated by an interval of 30 seconds. It is essential to instruct patients to try not to withhold the probe. Indeed, coaching patients while they perform maneuvers might enhance the accuracy of the test. In one study, coaching changed the diagnosis based on manometry from "pathologic" to "normal" values in 14 of 31 patients with incontinence and 12 of 39 patients with dyssynergic defecation. $^{21}$

\section{Graded Balloon Distension}

This maneuver consists of intermittent balloon distension in the rectum to assess rectal sensation and the recto-anal inhibitory reflex (RAIR). While the RAIR can generally be elicited by a volume of $15 \mathrm{~mL}$, it is efficient to inflate the balloon to $50 \mathrm{~mL}$ of air to assess this reflex. If no RAIR is recorded, the following measures may solve the problem: (1) ask the patient not to contract the external anal sphincter during rectal distension, (2) make sure there is no fecal impaction, and (3) raise the rectal distension volume.

To assess rectal sensation, the rectal balloon is initially distended with air in increments of $10 \mathrm{~mL}$, until the patient reports a first sensation. Thereafter, the balloon is increased in $20-\mathrm{mL}$ steps up to a maximum volume of $400 \mathrm{~mL}$. The distensions should be terminated earlier if the maximum tolerable volume is reached. Each distension is maintained for at least 30 seconds. Patients are asked to report sensations (first sensation, desire to defecate, urgency to defecate, and maximum tolerable sensation). Rectal compliance (ie, pressure-volume relationships) can also be measured during balloon distention. However, the rectal balloon used for HRM is relatively stiff. For example, when the Given HRM catheter balloon is inflated by $50 \mathrm{~mL}$ in atmosphere, it has a pressure of $137 \mathrm{mmHg}$. In theory, rectal compliance can be estimated by subtracting this pressure from the measured balloon pressure during rectal distention. However, in general, rectal compliance measured with a manometry is not as accurate as measurements with a barostat.

\section{Analysis and Interpretation of Traditional Anorectal Parameters}

Several small studies have evaluated normal values for anorectal measured with HR-ARM (or HD-ARM) catheters (Tables 2 and 3). ${ }^{7,22-27}$ However, because the sample size in these studies was relatively small, additional studies are necessary to more precisely define the normal range for anorectal pressures. The interpretation of findings will rely on studies conducted with HRM where available and supplemented by data from studies conducted with nonHRM only when necessary.

\section{Resting Anal Sphincter Pressure}

The internal anal sphincter (IAS) and external anal sphincter (EAS) maintain approximately $55 \%$ and $30 \%$ of anal resting tone, respectively; the remainder $(15 \%)$ is generated by the hemorrhoidal plexus. ${ }^{28}$ At best, these figures are estimates because they were partly obtained from complex studies in which anal resting pressure was sequentially recorded before surgery (ie, abdominoperineal resection), after curarization, and in the resected specimen before and after verapamil. ${ }^{29}$

Similar to non-HRM, normal values for anal resting pressure measured with HRM is dependent on sex and age. The maximal resting sphincter pressure is significantly lower in women than in men. ${ }^{24,27}$ Increasing age is associated with a lower anal resting pressure. $^{22,23,27}$ Interestingly, anal resting pressure in healthy women was lower in a study from Korea ${ }^{24}$ than in different studies from the United States and Europe. ${ }^{7,22,26}$ These differences are more likely explained by differences in techniques rather than ethnic differences because anal pressures in healthy Asian volunteers ${ }^{23,25}$ were similar to those from a group that included participants from Western countries. ${ }^{7,22,26}$ The HR-ARM system (Sandhill Scientific) used in the Korean study ${ }^{24}$ averages anal pressures across radial sensors at any level of the catheter. This might explain why pressures measured with the Sandhill HR-ARM catheter are lower than those measured with the eSleeve program (Given Imaging HR-ARM and HD-ARM). ${ }^{30}$

\section{Increased pressure}

In a cohort of 295 constipated women studied with HR-ARM, 36 patients (12\%) had low and 12 patients (4\%) had high anal resting pressures. ${ }^{26}$ High anal resting pressure may suggest smooth muscle or striated muscle spasm. ${ }^{18}$ High anal pressures often occur in patients with anal fissure or anal pain. In a study conducted 


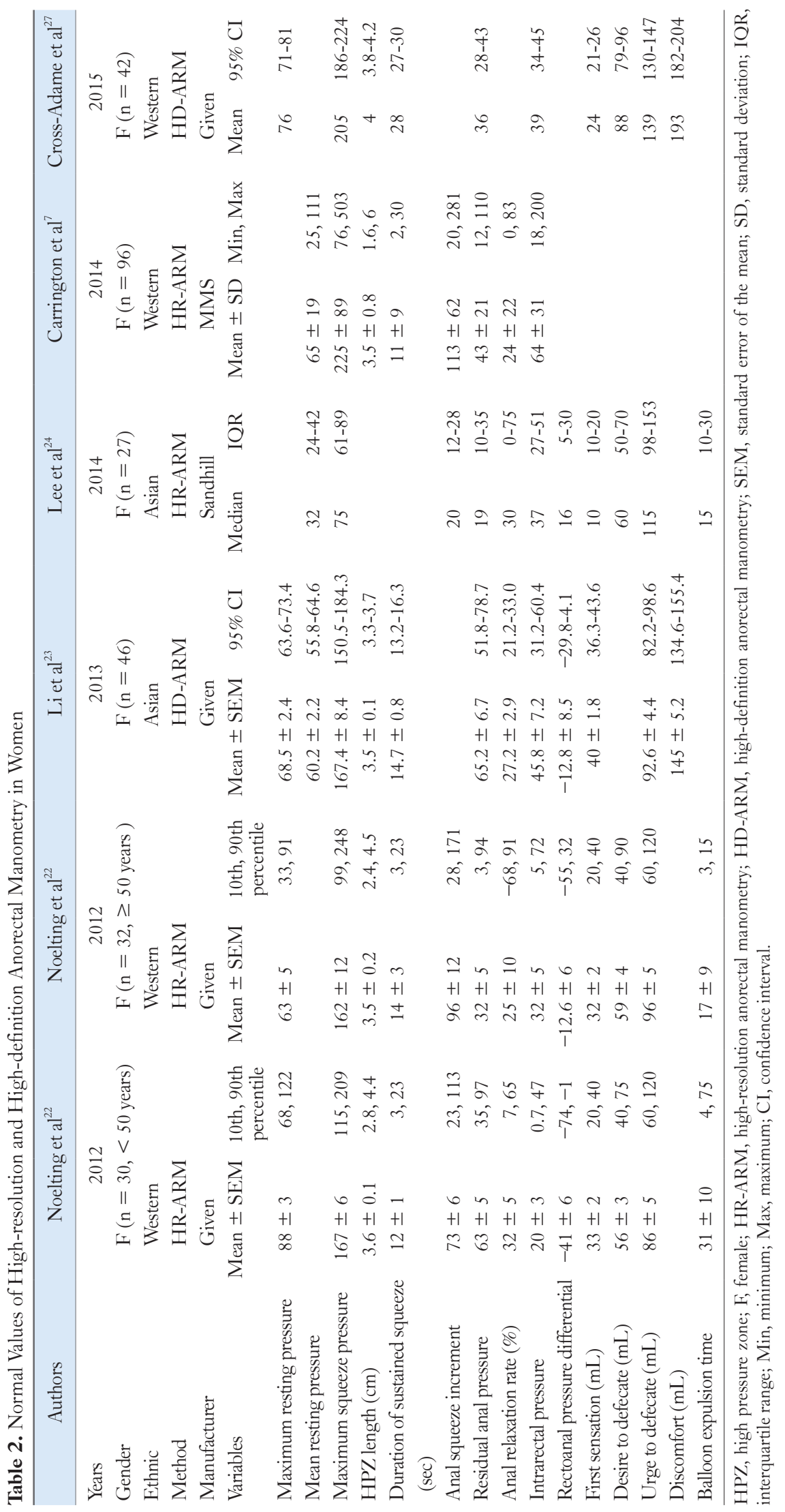


Table 3. Normal Values of High-resolution and High-definition Anorectal Manometry in Men

\begin{tabular}{|c|c|c|c|c|c|c|c|c|}
\hline Authors & \multicolumn{2}{|c|}{ Li et $\mathrm{al}^{23}$} & \multicolumn{2}{|c|}{ Lee et $\mathrm{al}^{24}$} & \multicolumn{2}{|c|}{ Carrington et $\mathrm{al}^{7}$} & \multicolumn{2}{|c|}{ Cross-Adame et $\mathrm{al}^{27}$} \\
\hline Years & \multicolumn{2}{|c|}{2013} & \multicolumn{2}{|c|}{2014} & \multicolumn{2}{|c|}{2014} & \multicolumn{2}{|c|}{2015} \\
\hline Gender & \multicolumn{2}{|c|}{$M(n=64)$} & \multicolumn{2}{|c|}{$M(n=27)$} & \multicolumn{2}{|c|}{$M(n=19)$} & \multicolumn{2}{|c|}{$\mathrm{M}(\mathrm{n}=36)$} \\
\hline Ethnic & \multicolumn{2}{|l|}{ Asian } & \multicolumn{2}{|c|}{ Asian } & \multicolumn{2}{|c|}{ Western } & \multicolumn{2}{|c|}{ Western } \\
\hline Method & \multicolumn{2}{|c|}{ HD-ARM } & \multicolumn{2}{|c|}{ HR-ARM } & \multicolumn{2}{|c|}{ HR-ARM } & \multicolumn{2}{|c|}{ HD-ARM } \\
\hline Manufacturer & \multicolumn{2}{|l|}{ Given } & \multicolumn{2}{|c|}{ Sandhill } & \multicolumn{2}{|c|}{ MMS } & \multicolumn{2}{|c|}{ Given } \\
\hline Variables & Mean \pm SEM & $95 \% \mathrm{CI}$ & Median & IQR & Mean $\pm \mathrm{SD}$ & Min, Max & Mean & $95 \% \mathrm{CI}$ \\
\hline Maximum resting pressure & $69.5 \pm 2.2$ & $65.2-73.8$ & & & & & 90 & $83-96$ \\
\hline Mean resting pressure & $61.3 \pm 2.1$ & $56.5-65.5$ & 46 & $39-56$ & $73 \pm 23$ & 38,136 & & \\
\hline Maximum squeeze pressure & $194.8 \pm 6.9$ & $180.9-208.6$ & 178 & $140-212$ & $290 \pm 155$ & 94,732 & 266 & $245-287$ \\
\hline HPZ length $(\mathrm{cm})$ & $3.6 \pm 0.1$ & $3.4-3.8$ & & & $3.9 \pm 0.8$ & $2.4,5.3$ & 4.3 & $4.1-4.5$ \\
\hline Duration of sustained squeeze (s) & $12.3 \pm 0.7$ & $10.8-13.8$ & & & $16 \pm 11$ & 3,30 & 30 & $28-30$ \\
\hline Anal squeeze increment & & & 55 & $41-77$ & $144 \pm 116$ & 40,474 & & \\
\hline Residual anal pressure & $81.2 \pm 4.3$ & $72.6-89.7$ & 26 & $13-55$ & $57 \pm 23$ & 20,104 & 40 & $28-52$ \\
\hline Anal relaxation rate $(\%)$ & $22.5 \pm 2.9$ & $16.6-28.3$ & 16 & $0-82$ & $16 \pm 33$ & 0,60 & & \\
\hline Intrarectal pressure & $72.3 \pm 9.4$ & $53.5-91.2$ & 69 & $44-98$ & $71 \pm 33$ & 20,140 & 43 & $35-51$ \\
\hline Rectoanal pressure differential & $-13.4 \pm 7.5$ & $-28.5-1.7$ & 30 & $5-66$ & & & & \\
\hline First sensation (mL) & $44.2 \pm 1.8$ & $40.6-47.8$ & 10 & $10-20$ & & & 22 & $20-25$ \\
\hline Desire to defecate (mL) & & & 80 & $60-120$ & & & 94 & $82-103$ \\
\hline Urge to defecate (mL) & $102.5 \pm 4.1$ & $94.2-110.8$ & 130 & $110-178$ & & & 163 & $140-167$ \\
\hline Discomfort (mL) & $154.5 \pm 3.7$ & $147.1-162$ & & & & & 206 & $192-222$ \\
\hline Balloon expulsion time & & & 15 & $5-50$ & & & & \\
\hline
\end{tabular}

HPZ, high pressure zone; SEM, standard error of the mean; SD, standard deviation; IQR, interquartile range; Min, minimum; Max, maximum; CI, confidence interval.

with a non-HRM catheter, patients with anal fissure and ultra-slow pressure waves had greater tone in the IAS, weaker IAS relaxation, and enhanced after-contraction following rectal distension, which raise the possibility of impaired nitrergic innervation of the IAS. ${ }^{31}$

\section{Decreased pressure}

In a study that assessed anal pressures with HRM and pelvic floor anatomy with magnetic resonance imaging in 119 patients with anorectal disorders, internal and external sphincter injury and a patulous canal, but not puborectalis injury, predicted anal resting pressure. ${ }^{32}$ In this study, reduced anal resting pressure had a sensitivity of $51 \%$ and a specificity of $70 \%$ for identifying injury of the IAS or a patulous canal. ${ }^{32}$ However, it should be noted that the normal range of anal pressures is relatively wide; for example, from 33-91 mmHg among women aged greater than 50 years in 1 study with $\mathrm{HRM}^{22}$

\section{Length of the high-pressure zone}

This is automatically determined by the software. For the Sierra HRM system, the length of the high-pressure zone (HPZ) is the length of the average pressure profile in the resting pressure frame defined as $\{$ rectal pressure $+[$ (anal resting pressure - rectal pressure $\times 0.25]\}$. $^{22}$ In asymptomatic women, the HPZ is, on average, $3.5 \mathrm{~cm}$ long, and not correlated with age. ${ }^{22}$ In one study, a longer HPZ was associated with a specific phenotype among patients with defecatory disorders. ${ }^{26}$ Intuitively, a longer HPZ probably reflects a more effective continence mechanism. However, further studies are required to assess the utility of measuring the dimensions of the HPZ for discriminating between healthy people and patients with fecal incontinence.

\section{Squeeze Pressure}

Contraction of the EAS is assessed by measuring the pressure when the anal sphincter is voluntarily contracted. Squeeze pressures are lower in women than men and in older than younger people. ${ }^{22-24,27}$ Hence, normal values are stratified by age and sex. The absolute squeeze pressure and the change from the resting pressure should be considered when interpreting the test.

\section{Increased pressure}

Older studies with non-high-resolution sensors have anecdotally reported high squeeze pressures and impaired anal relaxation 
during straining in men with chronic pelvic pain. ${ }^{18}$

\section{Decreased pressure}

Decreased pressures may be due to patient noncompliance or weakness of the EAS due to muscle or nerve injury. Studies with non-HRM suggested that a history of sexual abuse was associated with lower squeeze pressure even in the absence of anal sphincter injury. ${ }^{33}$ Weak squeeze pressures (and resting pressure) have been shown to be relatively insensitive for identifying sphincter injury or a patulous anal canal. ${ }^{32}$ However, the specificity of reduced squeeze pressure in detecting EAS or puborectalis muscle (PRM) injury or a patulous anal canal is higher. Consequently, an imaging study may not be necessary when anal resting or squeezing pressures are normal.

\section{Duration of squeeze}

The EAS is an unusual skeletal muscle because it muscle maintains resting tone. ${ }^{29}$ This resting or tonic activity is partly maintained by the fiber distribution, ie, type 1 (ie, fatigue-resistant, slow twitch) fibers predominate in the human anal sphincter, as opposed to type 2 or fast-twitch muscle fibers in cats and rabbits. The clinical significance of low squeeze duration measured with HR-ARM is unknown. A squeeze duration less than 10 seconds measured with non-HR-ARM, suggests reduced endurance, which was associated with impaired continence for liquid but not formed stools. ${ }^{34}$

\section{Cough Reflex}

Increased intra-abdominal pressure, for example during coughing, induces reflex contraction of the EAS. This reflex screens for damage to the sacral reflex arc. ${ }^{18}$ A low squeeze pressure and a normal cough reflex may reflect impaired volitional control of the EAS and/or damage of the central motor pathways above the sacral segments of the spinal cord. However, reduced squeeze pressure and an abnormal cough reflex suggest a defect in the sacral reflex arc. The anal pressure change during cough reflex was recorded $10 \mathrm{mmHg}$ greater by HR-ARM than non-HRM; the difference between 2 methods was not statistically significant. ${ }^{11}$

\section{Simulated Evacuation}

Normal defecation involves increased rectal pressure coordinated with relaxation of the anal sphincters and pelvic floor. ${ }^{18}$ Anal manometry in patients with defecatory disorders may disclose impaired relaxation or inappropriate contraction of the pelvic floor muscles and/or inadequate propulsive forces during simulated evacuation. The term simulated evacuation is preferred to defecation because the assessment lacks some features of defecation (eg, rectal distention by stool). It should be noted that laboratory conditions may induce inappropriate contractions of the pelvic floor ${ }^{35}$ due to the patient's fear of incontinence or his or her embarrassment. ${ }^{18}$

\section{Rectoanal pressure gradient and rectoanal index}

The relationship between rectal and anal pressure during simulated evacuation provides a measure of the physical forces during simulated evacuation. During normal defecation, it is intuitive that rectal pressure should exceed anal pressure, as manifest by a rectoanal index (ie, the ratio of rectal to anal pressure) greater than 1 or a positive rectoanal pressure gradient (RAPG). A rectoanal index less than 1.3 has been used to diagnose dyssynergia with non-HRM. ${ }^{36}$ However, several studies have observed that approximately $20 \%$ of asymptomatic people have dyssynergic defecation during nonHRM. $^{37}$ Likewise, the RAPG during simulated evacuation measured with HR-ARM and HD-ARM is often negative in healthy people. ${ }^{21,22,26}$ Indeed, depending on the technique, age and sex, a RAPG as low as $-71 \mathrm{mmHg}$ during simulated defecation may be regarded as "normal." "10,21,22 Hence, the utility of a negative RAPG as a marker of defecatory disorders is unclear because of the considerable overlap in this gradient among healthy individuals and constipated patients with and without a defecatory disorder. ${ }^{26}$ Likewise, the rectoanal index assessed with HRM did not discriminate between early and delayed balloon expulsion. ${ }^{8}$

Why the RAPG is negative in healthy people is unclear. Sauter et $\mathrm{al}^{10}$ hypothesized that simulated defecation may drive the recording catheter against the wall of the anal canal, producing "contact pressure." ${ }^{10}$ It is conceivable that the complete relaxation of the anal sphincter seen on non-HRM is an artifact caused by movement of the pressure sensors out of the anal sphincter during abdominal straining. In one study, a significant displacement of the catheter during simulated evacuation was observed in $55 \%$ of overall healthy individuals, which might tend to exaggerate anal relaxation during this maneuver. ${ }^{10}$ This does not affect HR-ARM because the topographic display makes it easier for the operator to minimize probe movement during the procedure.

\section{Types of pelvic floor dyssynergia}

In a study of 100 constipated patients, 4 patterns were identified during assessment of simulated evacuation with non-HRM. All these patterns are characterized by paradoxical contraction or a failure of anal relaxation (Fig. 2$)^{38}$ : a paradoxical increase in anal pressure with (type I) or without (type II) an adequate increase in rectal pressure and impaired anal relaxation with (type III) or with- 

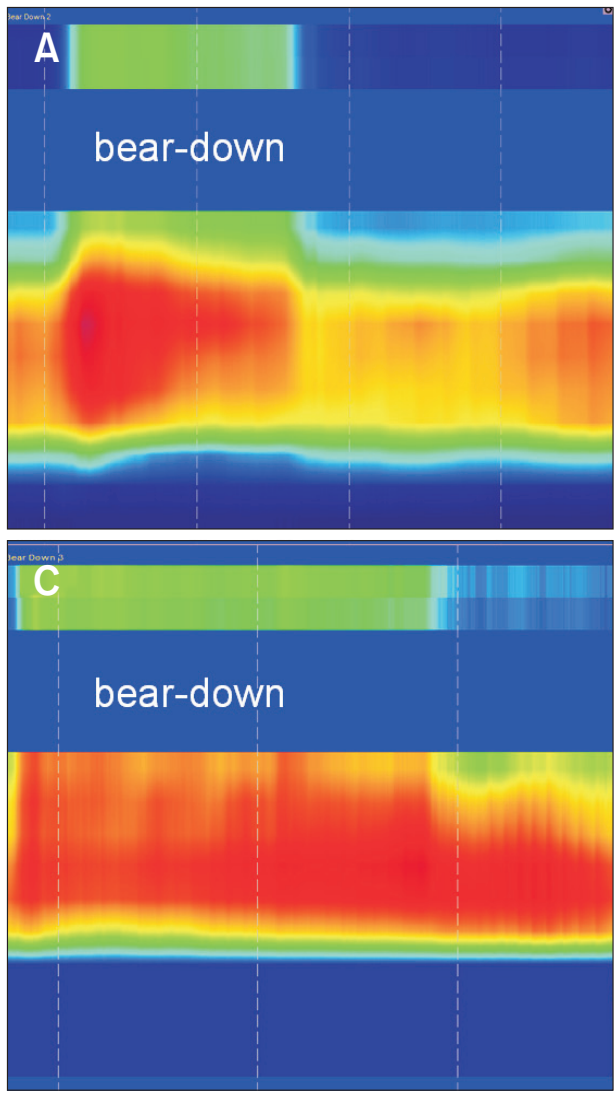

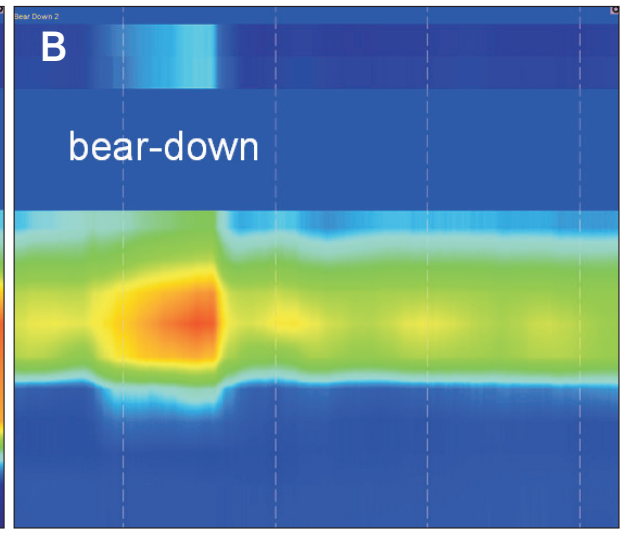

D

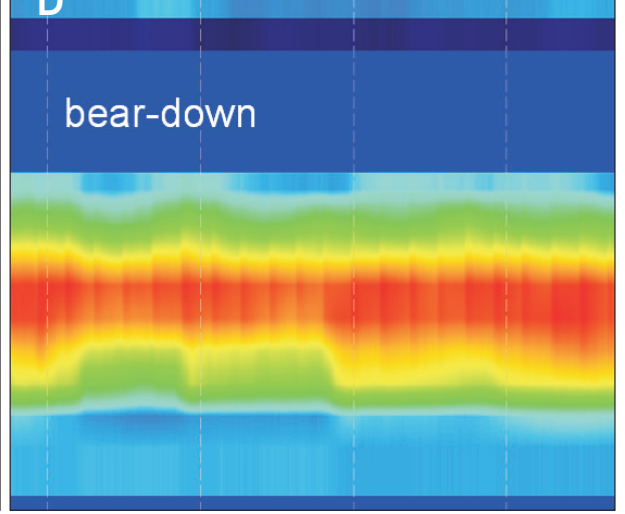

Figure 2. Types of pelvic floor dyssynergia seen with high-resolution anorectal manometry. (A) Type I dyssynergia: an adequate increase in rectal pressure ( $\geq 40 \mathrm{mmHg}$ ) accompanied by a paradoxical simultaneous increase in anal pressure. (B) Type II dyssynergia: an inadequate increase in rectal pressure $(<$ $40 \mathrm{mmHg}$; poor propulsive force) accompanied by a paradoxical simultaneous increase in anal pressure. (C) Type III dyssynergia: an adequate increase in rectal pressure ( $\geq 40 \mathrm{mmHg}$ ) accompanied by a failed reduction in anal pressure ( $\leq 20 \%$ baseline pressure). (D) Type IV dyssynergia: an inadequate increase in rectal pressure of $(<40$ $\mathrm{mmHg}$; poor propulsive force) accompanied by a failed reduction in anal pressure ( $\leq 20 \%$ baseline pressure). out (type IV) an adequate increase in rectal pressure.

Since this study was limited to patients, it is unclear whether these patterns can discriminate between healthy people and patients with defecatory disorders. An assessment of 188 patients with HRARM and MRI observed that HR-ARM had a sensitivity of $77 \%$ and a specificity of $85 \%$ for identifying dyssynergia documented with MRI. ${ }^{39}$ However, this study was uncontrolled. ${ }^{39}$

A principal components analysis of HR-ARM studies in 62 healthy women and 295 women with chronic constipation identified 4 phenotypes that discriminated healthy people from patients with abnormal balloon expulsion times; 2 phenotypes discriminated healthy people from those with constipation but normal balloon expulsion time. Phenotypes were characterized based on high anal pressure at rest and during evacuation (high anal pattern), only low rectal pressure during evacuation (low rectal pattern), low rectal pressure with impaired anal relaxation during evacuation (hybrid pattern), and a short anal high pressure zone (Fig. 3). ${ }^{26}$ This approach (principal component analysis) was $75 \%$ sensitive and $75 \%$ specific in discriminating healthy individuals from constipated patients with a prolonged balloon expulsion time. ${ }^{26}$ There is substantial agreement among expert observers for the overall diagnosis

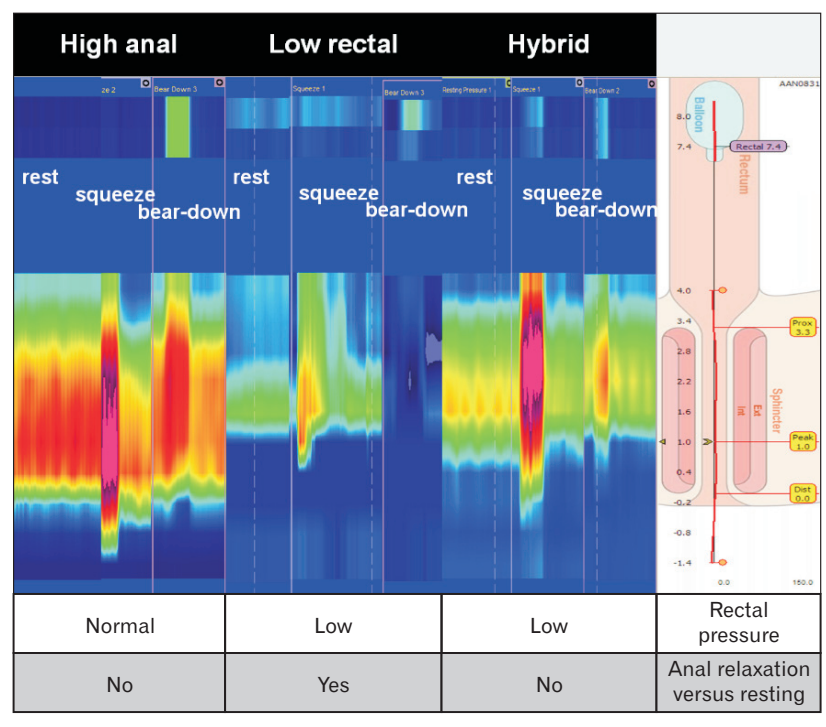

Figure 3. Three anorectal pressure phenotypes identified by high-resolution anorectal manometry in patients with dyssynergic defecation.

of a functional defecation disorder (kappa $=0.63$ ) or the individual patterns, ie, type I (kappa $=0.71)$, IV dyssynergia $(\mathrm{kappa}=0.61)$, normal pattern $($ kappa $=0.47)$, type II $($ kappa $=0.40)$, and III 
dyssynergia (kappa $=0.35) .{ }^{37}$ However, dyssynergia is not useful for discriminating between healthy people and patients because $90 \%$ of healthy volunteers and patients with functional constipation had an abnormal anorectal pressure profile during simulated defecation. ${ }^{37}$ Only type IV dyssynergia had a positive likelihood ratio of 2.3 , indicative of a "small" increase in the likelihood of disease. ${ }^{37}$

\section{Recto-anal Inhibitory Reflex}

This reflex is an integral part of normal defecation. It is manifest as a reduction in anal pressure during rectal balloon distention. ${ }^{40}$ The amplitude and duration of the RAIR depend on the rate and volume of rectal distention. ${ }^{41}$ RAIR is absent in several conditions, including dysganglionosis, postcircular myotomy, and lower anterior resections. ${ }^{42}$ In a systematic review, the diagnostic utility of the absence of RAIR in Hirschsprung's disease, as detected by non-HRM, had a sensitivity of $91 \%$ and specificity of $94 \% .{ }^{43} \mathrm{~A}$ recent HD-ARM study found that RAIR is characterized by a differential relaxation along the anteroposterior axis, the length of the anal canal, and at each vector, with the maximum change occurring at the level of the IAS. ${ }^{40}$ There have been no studies assessing the RAIR with HR-ARM in Hirschsprung's disease.

\section{Rectal Sensation}

Rectal sensation is evaluated by measuring the perception (eg, first sensation, urge to defecate, and discomfort) of rectal distention. The normal values for rectal sensation also depend on the stiffness and configuration of the rectal balloon. All HR-ARM and HDARM systems recommend use of a non-latex balloon that is less elastic. Further studies are required to compare rectal sensation evaluated with non-high resolution and HRM.

\section{Increased perception}

In studies conducted with non-HRM catheters, urge fecal incontinence, proctitis, or irritable bowel syndrome were associated with rectal hypersensitivity.

\section{Decreased perception}

In the only study that compared rectal sensation assessed with a HRM catheter in healthy people and disease, the rectal sensory threshold for the desire to defecate was greater, suggesting reduced sensation, in patients with a defecatory disorder and abnormal rectal balloon expulsion. ${ }^{26}$ Biofeedback training can improve rectal sensation in patients with reduced rectal sensation. ${ }^{18,44}$

\section{Interpretation of High-resolution Manometry Color Plots}

Colors are assigned to the pressures, with cool colors (blue and green) for lower pressures and warm colors (red and yellow) for high pressures. ${ }^{45}$ Color contour plots provide a more intuitive understanding of pressure profiles, such as those indicating anal weakness and relaxation. ${ }^{46}$

\section{Interpreting High-resolution Anorectal Manometry Color Contour Plots}

Anal pressures and the length of the HPZ can be instantly gauged by visualizing the contour plot at rest. During squeeze, 2 distinct HPZs may be seen ${ }^{7}$; the upper and lower zones are above and overlap the anal HPZ, and presumably represent contraction of the PRM and EAS, respectively. As noted above, rectal pressure may not increase and anal relaxation may be delayed during simulated evacuation, even in healthy adults.

\section{High-definition Anorectal Manometry Color Con- tour Plot Interpretations}

HD-ARM studies can be analyzed in 2-dimensions (2-D) and 3-D. With 3-D maps, the resting frame shows a dumb-bell shape, with a high-pressure ring in the middle and low-pressure areas on both ends (Fig. 4A). Two-dimensional maps show a high-pressure band in the middle of the image. ${ }^{23,25}$ During normal anal contraction (squeeze), the 3-D map depicts an "hourglass" appearance while the 2-D map has a " $\lambda$ " shape (Fig. 4B). ${ }^{12,23,25}$ The cranial and caudal edges of the PRM and the EAS on 3-D maps correspond to cranial, and caudal edges of the anal canal on the 3D-ultrasound, respectively. ${ }^{47}$ The length of anal canal determined by HD-ARM is slightly but significantly longer than the one measured by $3 \mathrm{D}$ ultrasound images. ${ }^{47}$

During normal simulated evacuation, high intrarectal pressure and anal relaxation generate a tube that tapers proximally and has been described as a trumpet on 3-D mapping. ${ }^{23}$ However, consistent with the observed variations in the rectoanal pressure profile during simulated evacuation in healthy women, this profile is not universal (Fig. 4C). 2-D mapping of simulated evacuation shows a red $\mathrm{HPZ}$ in the rectum and upper anal canal with a blue and green (low-pressure) zone more distally (ie, a low-pressure area in the distal posterior wall of the anorectum). ${ }^{23,25}$

In patients with paradoxical puborectalis contraction during simulated evacuation, 3-D mapping may reveal a characteristic 

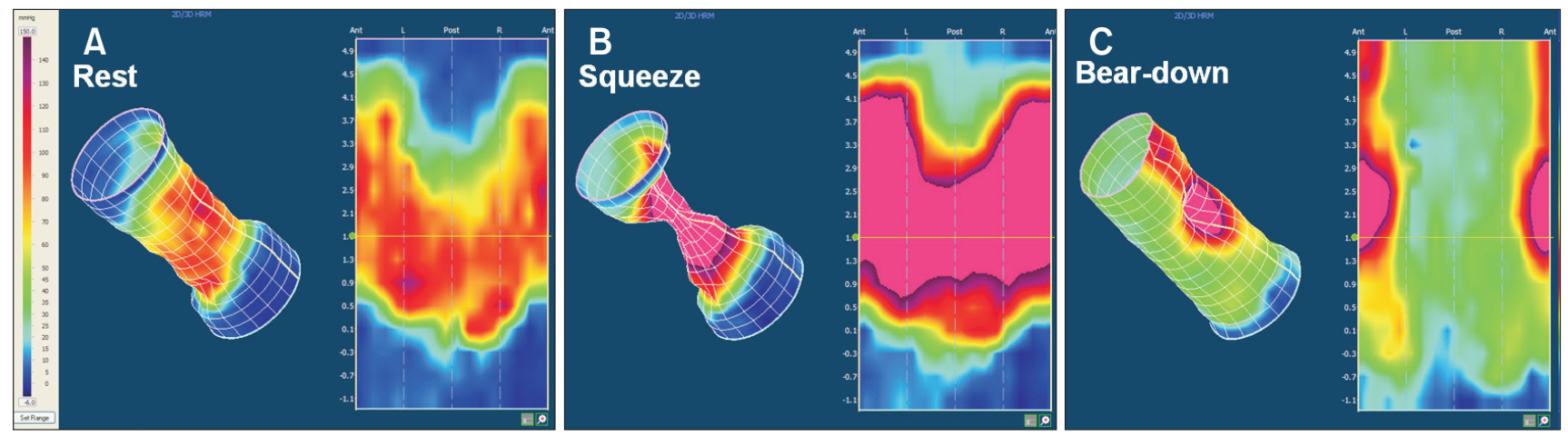

Figure 4. High definition anorectal manometry in a healthy individual. (A) Rest frame shows the high-pressure band is seen in the middle of the image. (B) Squeeze frame shows an " $\lambda$ " shape on 2-D mapping indicating normal functioning of the EAS muscle. (C) Bear-down frame shows a green low-pressure zones appearing in the end (ie, a low-pressure area in the distal posterior wall of the anorectum).
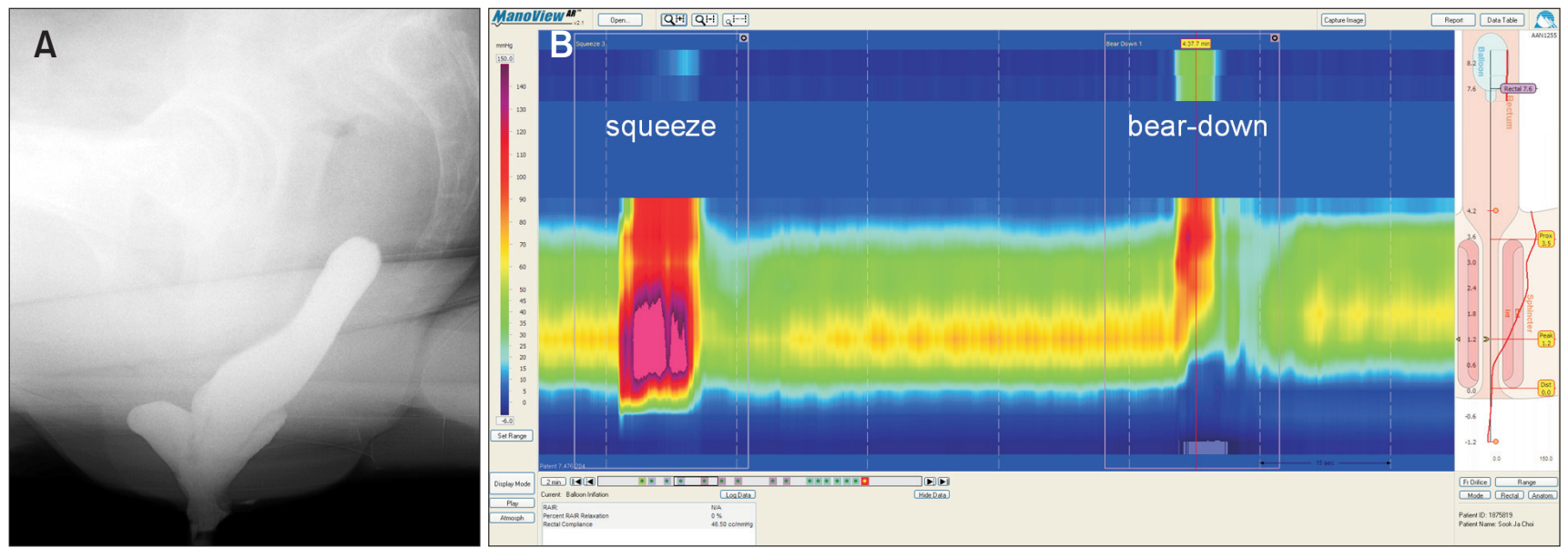

Figure 5. Defecogram and high-resolution anorectal manometry in the same individual. (A) Defecography shows rectocele and intussusception. (B) An increase in rectal pressure and a localized high-pressure band at the level of the anal sphincter during bearing down are seen on manometry.

posteriorly situated high-pressure area at the upper end the anal sphincter. ${ }^{25}$ This finding probably reflects incomplete relaxation or paradoxical contraction of the PRM and EAS. In 1 study, the pressure in this zone, which is situated $3 \mathrm{~cm}$ from the anal verge, was significantly higher in 79 patients with paradoxical puborectalis syndrome $(152.7 \pm 4.8 \mathrm{mmHg})$ than in 71 healthy adults $(88.0 \pm$ $5.9 \mathrm{mmHg})^{25}$

\section{Integrated Pressurization Volume}

Similar to the concept of integrated relaxation pressure used for esophageal HRM ${ }^{14}$ a recent HR-ARM study measured the integrated pressurized volume (IPV) as a measure of anal relaxation during simulated evacuation. ${ }^{8}$ The IPV not only reflects the anal pressure (amplitude), but also the duration of relaxation and the spatial component (ie, length of anal canal). In this study, the IPV but not anal pressure alone, was correlated, albeit weakly, with the balloon expulsion time.

\section{Evaluation of Structural Pathology}

The asymmetry in anal canal pressure results from overlap between the IAS, EAS, and PRM and the unique triple-looped anatomy of the $\mathrm{EAS}^{48}$ Because the sphincter muscles overlap it is not possible to separate the contributions of the IAS and EAS to anal resting pressure. It seems intuitive that the pressure increment during squeeze probably reflects external anal sphincter function in the resting anal HPZ and the PRM in the region above the HPZ. ${ }^{40,47,49}$ However, these inferences need to be confirmed by further studies in patients with selective dysfunction of a muscle or 
with pharmacological approaches. Moreover, spatial resolution is limited by the distance between adjacent sensors (eg, $6 \mathrm{~mm}$ for the HR-ARM catheter manufactured by Given Imaging). Pressure values in between sensors are obtained by software-based interpolation of pressures rather than actual values, which limits the precision of these measurements at the upper end of the anal canal.

It is suggested that the increased rectal pressure with a narrow band of high pressure within the anal canal during simulated evacuation suggests rectal intussusception (Fig. 5). ${ }^{39}$ While this is conceivable, it needs to be confirmed with further studies that simultaneously evaluate rectoanal pressures and rectal evacuation. Two studies suggest that perineal descent measured with HDARM significantly correlated with that measured with barium defecography. ${ }^{50,51}$ However, this assumes that the position of the $\mathrm{HD}-\mathrm{ARM}$ catheter relative to the anal canal is the same before and during simulated evacuation. In our experience, this can be challenging. Also, the Bland Altman plots suggest that the difference in perineal descent measured with defecography and HD-ARM was related to the magnitude of perineal descent. ${ }^{51}$

While it has been suggested that HD-ARM can be used to visualize sphincter defects, only 1 study has compared anal manometry with an imaging assessment, specifically with endoanal ultrasound. $^{52}$ In that study of 100 patients, of whom 93 were women, HD-ARM identified $86 \%$ of IAS and $79 \%$ of EAS defects visualized with endoanal ultrasound. With manometry, anal sphincter defects were arbitrarily defined as a continuous circumferential area over which the anal resting pressure was less than $10 \mathrm{mmHg}$ and absence of voluntary contraction for IAS defects and EAS defects, respectively. However, the false positive rate $41 \%$ for IAS and $30 \%$ for EAS defects. ${ }^{52}$ The kappa statistic for the agreement between HD-ARM and endoanal ultrasound was 0.42 for the internal and 0.46 external anal sphincter, which reflects moderate agreement between the techniques. Based on these data, HD-ARM cannot be recommended as a substitute to imaging for identifying anal sphincter defects. However, further studies are necessary to address this issue.

\section{Conclusions}

HR-ARM and HD-ARM catheters incorporate a large number of closely-spaced pressure sensors that provide better spatiotemporal resolution than is obtained with non-HRM. ${ }^{9,10,12}$ In contrast to HR-ARM, HD-ARM also displays the data for individual pressure sensors around the circumference (ie, radial asymmetry). However, there is limited evidence to suggest that HD-ARM can discriminate between function of the EAS and PRM or accurately identify anal sphincter defects. Also, HR-ARM and HD-ARM are of limited utility for discriminating between healthy people and defecatory disorders. Further studies are necessary to evaluate the incremental clinical utility of HR-ARM versus non-high resolution manometry.

Financial support: Dr. Bharucha was partly supported by NIH Grants R01 DKDK78924 from the National Institutes of Health (NIH). This work was partly supported by the Soonchunhyang University Research Fund.

\section{Conflicts of interest: None.}

\section{References}

1. Bharucha AE. Difficult defecation: difficult problem assessment and management; what really helps? Gastroenterol Clin North Am 2011;40: 837-844.

2. Bharucha AE, Pemberton JH, Locke GR 3rd. AGA practice guideline on constipation: technical review. Gastroenterology 2013;144:218-238.

3. Bharucha AE, Rao SS. An update on anorectal disorders for gastroenterologists. Gastroenterology 2014;146:37-45.

4. Wald A, Bharucha AE, Cosman BC, Whitehead WE. ACG clinical guideline: management of benign anorectal disorders. Am J Gastroenterol 2014;109:1141-1157

5. Rao SS. Pathophysiology of adult fecal incontinence. Gastroenterology 2004;126( suppl 1):S14-S22.

6. Bharucha AE, Fletcher JG, Harper CM, et al. Relationship between symptoms and disordered continence mechanisms in women with idiopathic faecal incontinence. Gut 2005;54:546-555.

7. Carrington EV, Brokjaer A, Craven $\mathrm{H}$, et al. Traditional measures of normal anal sphincter function using high-resolution anorectal manometry (HRAM) in 115 healthy volunteers. Neurogastroenterol Motil 2014;26: 625-635.

8. Jung KW, Joo S, Yang DH, et al. A novel high-resolution anorectal manometry parameter based on a three-dimensional integrated pressurized volume of a spatiotemporal plot, for predicting balloon expulsion in asymptomatic normal individuals. Neurogastroenterol Motil 2014;26:937949.

9. Jones MP, Post J, Crowell MD. High-resolution manometry in the evaluation of anorectal disorders: a simultaneous comparison with waterperfused manometry. Am J Gastroenterol 2007;102:850-855.

10. Sauter M, Heinrich H, Fox M, et al. Toward more accurate measurements of anorectal motor and sensory function in routine clinical practice: validation of high-resolution anorectal manometry and Rapid Barostat Bag measurements of rectal function. Neurogastroenterol Motil 2014;26:685-695.

11. Kang HR, Lee JE, Lee JS, et al. Comparison of high-resolution anorectal manometry with water-perfused anorectal manometry. J Neurogastro- 
enterol Motil 2015;21:126-132.

12. Lee YY, Erdogan A, Rao SS. High resolution and high definition anorectal manometry and pressure topography: diagnostic advance or a new kid on the block? Curr Gastroenterol Rep 2013;15:360.

13. Ambartsumyan L, Rodriguez L, Morera C, Nurko S. Longitudinal and radial characteristics of intra-anal pressures in children using 3D highdefinition anorectal manometry: new observations. Am J Gastroenterol 2013;108:1918-1928.

14. Babaei A, Lin EC, Szabo A, Massey BT. Determinants of pressure drift in Manoscan ${ }^{\mathrm{TM}}$ esophageal high-resolution manometry system. Neurogastroenterol Motil 2015;27:277-284.

15. Nguyen M, Cheeney G, Tantiphlachiva K, Valestin J, Attaluri A, Rao SS. Investigation of high-definition anorectal pressure topography (HDM) in patients with constipation and fecal incontinence [abstract]. Gastroenterology 2010;138:S30-S31.

16. Bredenoord AJ, Hebbard GS. Technical aspects of clinical high-resolution manometry studies. Neurogastroenterol Motil 2012;24(suppl 1):510.

17. Robertson EV, Lee YY, Derakhshan MH, et al. High-resolution esophageal manometry: addressing thermal drift of the manoscan system. Neurogastroenterol Motil 2012;24:61-64, e11.

18. Azpiroz F, Enck P, Whitehead WE. Anorectal functional testing: review of collective experience. Am J Gastroenterol 2002;97:232-240.

19. Wald A, Bharucha AE, Cosman BC, Whitehead WE. ACG clinical guideline: management of benign anorectal disorders. Am J Gastroenterol 2014;109:1141-1157.

20. Rao SS, Azpiroz F, Diamant N, Enck P, Tougas G, Wald A. Minimum standards of anorectal manometry. Neurogastroenterol Motil 2002;14:553-559.

21. Heinrich H, Fruehauf H, Sauter M, et al. The effect of standard compared to enhanced instruction and verbal feedback on anorectal manometry measurements. Neurogastroenterol Motil 2013;25:230-237, e163.

22. Noelting J, Ratuapli SK, Bharucha AE, Harvey DM, Ravi K, Zinsmeister AR. Normal values for high-resolution anorectal manometry in healthy women: effects of age and significance of rectoanal gradient. Am J Gastroenterol 2012;107:1530-1536.

23. Li Y, Yang X, Xu C, Zhang Y, Zhang X. Normal values and pressure morphology for three-dimensional high-resolution anorectal manometry of asymptomatic adults: a study in 110 subjects. Int J Colorectal Dis 2013;28:1161-1168.

24. Lee HJ, Jung KW, Han S, et al. Normal values for high-resolution anorectal manometry/topography in a healthy Korean population and the effects of gender and body mass index. Neurogastroenterol Motil 2014; 26:529-537.

25. Xu C, Zhao R, Conklin JL, et al. Three-dimensional high-resolution anorectal manometry in the diagnosis of paradoxical puborectalis syndrome compared with healthy adults: a retrospective study in 79 cases. Eur J Gastroenterol Hepatol 2014;26:621-629.

26. Ratuapli SK, Bharucha AE, Noelting J, Harvey DM, Zinsmeister AR. Phenotypic identification and classification of functional defecatory disorders using high-resolution anorectal manometry. Gastroenterology 2013; 144:314-322, e2.
27. Coss-Adame E, Rao SS, Valestin J, Ali-Azamar A, Remes-Troche JM. Accuracy and reproducibility of high-definition anorectal manometry and pressure topography analyses in healthy subjects. Clin Gastroenterol Hepatol 2015;13:1143-1150.

28. Penninckx F, Lestar B, Kerremans R. The internal anal sphincter: mechanisms of control and its role in maintaining anal continence. Baillieres Clin Gastroenterol 1992;6:193-214.

29. Bharucha AE. Pelvic floor: anatomy and function. Neurogastroenterol Motil 2006;18:507-519.

30. Lee HJ, Jung KW, Han S, Myung SJ. Normal values for high-resolution anorectal manometry: author's reply. Neurogastroenterol Motil 2014;26:1358-1359.

31. Opazo A, Aguirre E, Saldaña E, Fantova MJ, Clavé P. Patterns of impaired internal anal sphincter activity in patients with anal fissure. Colorectal Dis 2013;15:492-499.

32. Prichard D, Harvey DM, Fletcher JG, Zinsmeister AR, Bharucha AE. Relationship among anal sphincter injury, patulous anal canal, and anal pressures in patients with anorectal disorders. Clin Gastroenterol Hepatol 2015;13:1793-1800, e1.

33. Leroi AM, Berkelmans I, Denis P, Hémond M, Devroede G. Anismus as a marker of sexual abuse. Consequences of abuse on anorectal motility. Dig Dis Sci 1995;40:1411-1416.

34. Fox M, Schwizer W, Menne D, Stutz B, Fried M, Thumshirn M. The physical properties of rectal contents have effects on anorectal continence: insights from a study into the cause of fecal spotting on orlistat. Dis Colon Rectum 2004;47:2147-2156.

35. Duthie GS, Bartolo DC. Anismus: the cause of constipation? Results of investigation and treatment. World J Surg 1992;16:831-835.

36. Rao SS, Welcher KD, Leistikow JS. Obstructive defecation: a failure of rectoanal coordination. Am J Gastroenterol 1998;93:1042-1050.

37. Grossi U, Carrington EV, Bharucha AE, Horrocks EJ, Scott SM, Knowles CH. Diagnostic accuracy study of anorectal manometry for diagnosis of dyssynergic defecation. Gut Published Online First: 12 Mar 2015. doi:10.1136/gutjnl-2014-308835.

38. Rao SS. Dyssynergic defecation and biofeedback therapy. Gastroenterol Clin North Am 2008;37:569-586.

39. Heinrich H, Sauter M, Fox M, et al. Assessment of obstructive defecation by high-resolution anorectal manometry compared with magnetic resonance defecography. Clin Gastroenterol Hepatol 2015;13:13101317, e1.

40. Cheeney G, Nguyen M, Valestin J, Rao SS. Topographic and manometric characterization of the recto-anal inhibitory reflex. Neurogastroenterol Motil 2012;24:e147-e154.

41. Sun WM, Read NW, Prior A, Daly JA, Cheah SK, Grundy D. Sensory and motor responses to rectal distention vary according to rate and pattern of balloon inflation. Gastroenterology 1990;99:1008-1015 .

42. Sangwan YP, Solla JA. Internal anal sphincter: advances and insights. Dis Colon Rectum 1998;41:1297-1311.

43. de Lorijn F, Kremer LC, Reitsma JB, Benninga MA. Diagnostic tests in Hirschsprung disease: a systematic review. J Pediatr Gastroenterol Nutr 2006;42:496-505.

44. Gladman MA, Lunniss PJ, Scott SM, Swash M. Rectal hyposensitivity. 
Am J Gastroenterol 2006;101:1140-1151.

45. Müller M. Impact of high-resolution manometry on achalasia diagnosis and treatment. Ann Gastroenterol 2015;28:3-9.

46. Clouse RE, Staiano A, Alrakawi A, Haroian L. Application of topographical methods to clinical esophageal manometry. Am J Gastroenterol 2000;95:2720-2730.

47. Raizada V, Bhargava V, Karsten A, Mittal RK. Functional morphology of anal sphincter complex unveiled by high definition anal manometery and three dimensional ultrasound imaging. Neurogastroenterol Motil 2011;23:1013-1019.

48. Jung SA, Pretorius DH, Weinstein M, Nager CW, Den-Boer D, Mittal RK. Closure mechanism of the anal canal in women: assessed by threedimensional ultrasound imaging. Dis Colon Rectum 2008;51:932-939.

49. Cheeney G, Remes-Troche JM, Attaluri A, Rao SS. Investigation of anal motor characteristics of the sensorimotor response (SMR) using 3-D anorectal pressure topography. Am J Physiol Gastrointest Liver Physiol 2011;300:G236-G240.

50. Vitton V, Grimaud JC, Bouvier M. Three-dimension high-resolution anorectal manometry can precisely measure perineal descent. J Neurogastroenterol Motil 2013;19:257-258.

51. Benezech A, Bouvier M, Grimaud JC, Baumstarck K, Vitton V. Threedimensional high-resolution anorectal manometry and diagnosis of excessive perineal descent: a comparative pilot study with defaecography. Colorectal Dis 2014;16:O170-O175.

52. Vitton V, Ben Hadj Amor W, Baumstarck K, Behr M, Bouvier M, Grimaud JC. Comparison of three-dimensional high-resolution manometry and endoanal ultrasound in the diagnosis of anal sphincter defects. Colorectal Dis 2013;15:e607-e611. 